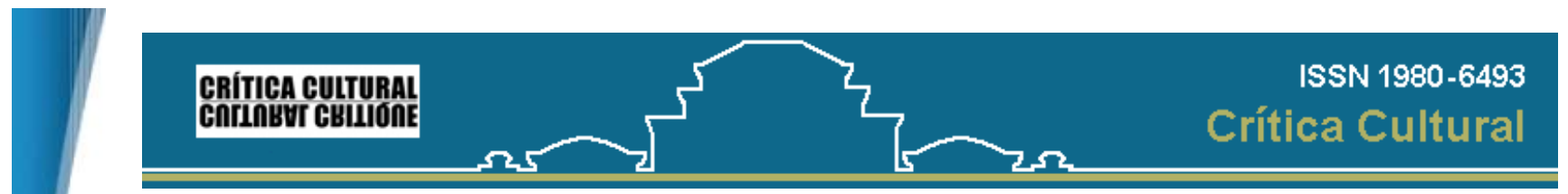

Crítica Cultural, volume 3, número 2, jul./dez. 2008

\title{
AS IMAGENS COMO FORÇA
}

Raul Antelo *

\begin{abstract}
Resumo: A partir da idéia de que as imagens são forças e não fatos ou formas, o ensaio elabora uma teoria da fotografia como o ocaso do sentido perseguindo as relações entre o contemporâneo e a imagem na antropofagia de Oswald de Andrade, em Marcel Mauss, Alfred Métraux, Georges Bataille, Murilo Mendes, Roland Barthes etc. Em seguida, refaz o percurso dos fotógrafos Horacio Coppola e Grete Stern para ilustrar um procedimento que se desvia do modernismo autonômico e letrado, lendo seus trabalhos como uma ficção sem autor, uma fulguração sem exterior, uma passagem instantânea do orgânico ao inorgânico, uma basculação entre obra e texto e um abandono da ação em favor da inoperância.
\end{abstract}

Palavras-chave: imagem, fotografia, modernismo.

\section{I ntrodução}

Como captar, nas imagens, a força do contemporâneo? Aliás, o que é o contemporâneo? Uma ficção sem autor sem exterior, poderíamos dizer. Uma passagem do orgânico ao inorgânico, da obra ao texto e da ação à inoperância. Não há como abordar o contemporâneo sem, ao mesmo tempo, encarar o trabalho da imaginação e seus dispositivos [1].

Arjun Appadurai revela-nos que, longe de funcionar como ocioso passatempo para as elites, a imaginação é um campo estruturado de práticas de massa. Ela é uma forma de trabalho culturalmente organizada, o que nos leva a reconsiderar a dimensão pública das imagens, decididas tanto pelos meios de comunicação quanto pelas migrações, ambos de massas [2]. Essa dimensão pública, tradicionalmente fruto da separação entre o privado e o social, há muito que já não se opõe à imaginação, digamos assim, individual ou "privada". Ela, pelo contrário, configura-a e a constitui, uma vez que definimos como público tudo aquilo que se pensa, simultaneamente, no interior e no exterior da acumulação.

Creio, no entanto, reconhecer, neste ponto, duas vertentes críticas. De um lado, a herança teórica de Frankfurt prioriza a questão da autonomia, mesmo porque seus mentores, dentre eles Walter Benjamin, estavam preocupados, fundamentalmente, com a reprodução técnica, que afetaria as subjetividades, daí em diante, anestesiadas; porém, é inegável também que, depois de Foucault, Deleuze e Derrida, não podemos ignorar que, ao questionar o falso movimento da historia, a própria crítica dialética acabou por reconhecer que se achava ela mesma em um teatro. A ênfase passou a cair não já na reprodução mas na repetição de valores e de formas. Eis o autêntico theatrum philosophicum da mundialização [3].

Nesse cenário pós-autonômico já não se debatem formas mas forças. Essas forças chamam-se imagens. São cifras, são enigmas, nos quais, da superposição $(\mathrm{o}$ com) de elementos dissímeis, a tradição e a ruptura, o trágico e o farsesco, surge o con-temporâneo. 0 teatro da repetição já não é o teatro da representação. Da mesma forma, o movimento das imagens já não comporta um conceito formal de globalização, mas o modo em que, sob seu regime, os corpos, a vida, são atualmente produzidos.

As imagens não são fatos [4]. Por isso, os críticos da autonomia caracterizam-se por pensar por imagens. Giorgio Agamben, grande leitor de Benjamin, antes mesmo de $O$ reino e a glória (2007), retornou a Aby Warburg e, em Mnemosyne nome desse atlante com memória (mnemo-syn) que sustentava o globo, constatou um modo de isolar a fórmula de expressão, a Pathosformel, da humanidade ocidental. Uma delas, em particular, a ninfa warburguiana, repousa sintomaticamente na ambigüidade estrutural da imagem. Como destaca Agamben,

la ninfa è l'immagine dell'immagine, la cifra delle Pathosformeln che gli uomini si trasmettono di generazione in generazione e a cui legano la loro possibilità di trovarsi o di perdersi, di pensare o di non pensare. Le immagini sono, pertanto, un elemento decisamente storico; ma, secondo il principio benjaminiano per cui si dà vita di tutto ciò di cui si dà storia (e che qui si potrebbe riformulare nel senso che si dà vita di tutto ciò di cui si dà immagine), esse sono, in qualche modo, vive [5].

A ninfa nos permite, então, pensar que o tempo da globalização só pode ser um tempo-com, um tempo nãocronológico mas anacrônico. Trata-se de uma participação temporal na temporalidade, ou seja que estamos diante de uma hiper-temporalização, infinita e potencializada, do evento singular que torna-se assim singular-p/ural. Em seu último livro, Signatura rerum, o mesmo Agamben nos alerta: a maneira menos criativa de ler os desdobramentos de Mnemosyne consiste em vê-los como um repertório iconográfico, em que a questão relevante seria a origem e evolução de um tema. 0 mais pertinente, entretanto, é reparar que nenhuma dessas imagens é original, mas nenhuma delas é mesmo réplica ou passiva reprodução de uma matriz, do que se conclui ser indecidível o estatuto de criação e ato, original e performance, já que as imagens seriam então híbridos de arquétipo e fenômeno. "Ogni fotografia è l'originale, ogni immagine costituisce l'arché, è in questo senso, arcaica; ma la ninfa stessa non è né arcaica né contemporanea, è un indecidibile di diacronia e sincronia, unicità e molteplicità" [6]. Essa imagem, a ninfa, é o paradigma, um esquema a rigor vazio, um Ur-fenômeno, de que cada ninfa singular é exemplo pleno.

Em vários de seus ensaios, Giorgio Agamben considera a linguagem poética como uma voz estranha, algo sem corpo próprio que, como o anjo da história de Klee e de Benjamin, empurrado por uma vertigem de vento, nos ultrapassa, infinitamente, ora em direção ao passado, ora ao futuro, para dissolver-se, finalmente, no silêncio. Poderíamos transferir essa raciocínio para as imagens. Sendo impossível afirmar a autonomia do sujeito, o eu que as contempla não passa de um simples punto de la nada- expressão de um discípulo de Unamuno, José Bergamin, que embute nessa expressão um discreto pleonasmo já que, em italiano ou francês, punto ou point são, justamente, palavras que conotam, elas mesmas, negação. Voltaremos a essa questão. Destaquemos, por enquanto, que a própria linguagem, ao tornar-se nada, um reles vazio, faz com que o autor, como antecipara Foucault, seja tão somente uma inexistência em cuja ausência se derrama, sem cessar, a linguagem incontida. Mas é porque o eu poético cristaliza-se, provisoriamente, nesse punto de la nada, como voz da linguagem ou como força da imagem, que se torna possível, afinal de contas, "encontrar un cuerpo y una carne, como su inútil habladuría, antes de sumirse para siempre en el silencio" [7]. Por isso Agamben resgata a separação traçada por Foucault entre a função-autor e o autor como indivíduo, distinção essa que lhe revela que a marca, a signatura, do artista reside na singularidade de sua ausência, aguardando-lhe, no jogo de ciframento, apenas o papel de morto. "L'autore non è mortodestaca Agamben-ma porsi come autore significa occupare il posto di un morto" [8].

A enunciação consiste em colocar-se no lugar do morto. Uma idéia como essa nos abre uma separação entre interpretação e decifração. Já no século XVIII, por exemplo, Giambattista Vico se voltava à sabedoria dos antigos egípcios par se questionar se o hieróglifo, através do qual eles se expressavam, escondia ou revelava um relato sagrado à consciência profana. Derrubando a idéia do poeta inspirado, centro da poética romântica, Vico considerava que o poeta antigo, produtor de fábulas, não conhecia a diferença moderna entre história e ficção e, em conseqüência, admitia que o artista moderno não inventa personagens mas tão somente cria abstrações através de imagens, razão pela qual o evento artístico moderno é sempre paradoxal e contraditório. Ele tanto pode ser pensado como imanência do logos no pathos, i.e. do pensamento no 
não-pensamento, quanto, ao contrário, como imanência do pathos no logos, do não-pensamento no pensamento. A primeira alternativa mostra a odisséia de um espírito lançado para fora dele mesmo, um espírito apolíneo que, atravessando a matéria, se manifesta muito além de si próprio, quer dizer, na dupla materialidade sensível da matéria e da imagem. O sentido, para o artista moderno, é, entretanto, algo que se busca mas, simultaneamente, oculta-se. Contra esta apática epopéia, teríamos a travessia contrária, que volta à coisa em si, ao mundo de uma vontade nua e crua que, no entanto, nada quer de próprio ou específico e, mesmo assim, à maneira baudelairiana, identifica bem e mal, prazer e sofrimento.

Esse caráter aporético da cifra, nome este último que, em árabe, é sinônimo de zero, nos leva a concluir que, na arte moderna, há pensamento na forma mesma do não-pensamento e, inversamente, afirmar que há um não-pensamento que habita todo pensamento e isto lhe confere à arte, em última instância, uma potência específica. Não é que o não-pensamento não seja nada. Ele é um vazio. Ele não é só ausência de pensamento mas presença efetiva de seu oposto ou, melhor dizendo, equivalência entre pensamento e não-pensamento, entre logos e mythos. Portanto, a potência do pensamento corresponde-se com um enigma que não é só manifestação da palavra, porém, fala muda ou tagarela, uma vez que a arte contemporânea fala e cala ao mesmo tempo. A polaridade entre essas duas ações define, afinal de contas, um lugar, o do sintoma, em outras palavras, assinala una coincidência, algo que cai com outra coisa, onde o mais relevante não é tanto o tombamento, 0 incidente ou incidência, mas o com, a conexão ou rede que esse abandono suscita. Daí que, enquanto sintoma, se possa definir a leitura como queda ou ocaso do sentido com outro tempo ou, ao mesmo tempo, com outros sentidos. Symptôma, tombamento, coincidência, acontecimento fortuito, encontro fadado ao insucesso, tyché [9].

Heidegger argumenta que quando o ser é pensado como infinito, é quando ele, precisamente, é mais determinado; mas se ele for pensado como finito, aí sua ausência-de-fundamento vem logo ser confirmada. Predicar a finitude, portanto, é postular a ausência de fundamento do sentido. Porém, não se trata, como argumenta Jean-Luc Nancy, de uma falha [manque] mas da constatação de que o ser não remete a nada, nem a uma substância, nem a um sujeito, nem mesmo ao ser mas a um ser-para, um ser para o mundo, um ser para si, que produz a abertura, o arrojo, o ser lançado para fora da existência [10]. Através da criação, esse infinito da presença acontece no finito, na imanência. Ele não é uma individuação nem uma geração, nem mesmo uma produção ou mediação dialética.

Esse valor da imagem é finito porque ele não sai de si ad extra, ele está escavado em si mesmo, por um recuo que dá lugar à abertura, onde se dispõem os singulares finitos. E é essa abertura, praticada e avaliada como vazio, que não se oferece nem se dá, mas que é um ser-com, a que conforma a disposição do mundo [11]. Portanto, a potência do pensamento se corresponde com uma gramática que não é só manifestação icônica mas, fundamentalmente, retirada ou ausência da própria imagem em ato. Ex acta, assim age a poesia que, como dizia Rimbaud, nos conduz à vertigem das imagens, uma prefiguração do cinema.

Georges Bataille argumentava que o pintor está sempre condenado a satisfazer o espectador e que, sob hipótese alguma, poderia transformar a sua obra em objeto de recusa.

Un espantapájaros tiene la finalidad de asustar a los pájaros, alejarlos del campo donde está enclavado, mientras que el cuadro más terrible está allí para atraer a los visitantes. Un suplicio real también puede despertar interés, pero en general no podría decirse que tenga e mismo fin: esto ocurre por un conjunto de razones; aunque en principio sus fines difieren poco de los espantapájaros: a la inversa del objeto de arte, se ofrece ante la vista para alejar del horror que expone. Mientras que el supliciado de los cuadros ya no intenta amonestarnos. El arte nunca se encarga de la tarea del juez. Por sí mismo no despierta interés en horro alguno: ni siquiera es imaginable. (....) Cuando el horror se ofrece a la transfiguración de un arte auténtico, lo que está en juego es un placer, un placer fuerte pero placer al fin [12].

Em outras palavras, já que a ação do artista contemporâneo, presente como ausência, consiste em falar e calar ao mesmo tempo, essa bipolaridade define, para a obra, um lugar, o do sintoma. Como sintoma, poderíamos então definir a leitura ou com-mentario [13] de uma imagem como a queda ou ocaso do sentido com outro tempo ou, ao mesmo tempo, com outros sentidos. Interpretar ou decifrar o texto-nos diz Nancy-não quer dizer levar a leitura em direção ao sentido, mas, ao contrário, recompor a cifra da letra. Não significa extrair o significado de seu invólucro, mas desenvolver a intriga: explicar, porém replicando o desdobramento do texto ou da imagem sobre si mesma [14].

Vamos historiar, ainda que de forma rápida, esse percurso na teoria da imagem. Em 1928, Oswald de Andrade formula uma teoria da arte, a antropofagia, que dispensa maiores explicações. Baste dizer que é uma metafísica do ser deslocado. Nesse mesmo ano, um antropólogo francês, discípulo de Marcel Mauss, publica uma tese sobre a antropofagia ritual em curiosa sintonia com Oswald. Alfred Métraux daria continuidade a essa pesquisa com um estudo sobre o sacrifício vodú. Entre os intelectuais do círculo bataillano, aplicados leitores de Nietzsche, dentre os quais figurava Métraux, havia outros que, como ele, sentiam-se também atraídos pela violência ritual das culturas latino-americanas. Poderíamos assim citar Roger Hervé, que se debruça sobre a cultura asteca, em artigo para Documents ilustrado por imagens do techcat/ (pedra sacrificial), imagens reunidas pioneiramente por Bernal Diaz del Castillo na Historia verídica de la conquista de la nueva España [15]. Caberia também lembrar de Ralph von Koenigswald e seu ensaio tanatológico ilustrado por cabeças xívaras [16]. Ou do ensaio de Michel Leiris sobre máscaras fúnebres [17]. Ou ainda o belíssimo texto de Georges Duthuit sobre representações da morte, ilustrado com uma cabeça reduzida mundurucá. Ou, por último, cabe ainda evocar as gravuras de antropofagia tupinambá de Théodore de Bry, que ilustram o livro de André Thévet [18], até chegarmos, claro, à atração de Bataille pelo suplício chinês, imagem esta oferecida a Bataille por seu próprio analista, o doutor Borel, e que estimula-o para sua análise da mutilação sacrificial de Van Gogh. Analisando, com efeito, duas telas do pintor holandês, Natureza morta com Bíblia aberta e $A$ cadeira de Gauguin, Georges Bataille julga que Gauguin desempenhou, perante Van Gogh, o papel das mais exaltadas aspirações do eu, marcando essas figuras com alguns traços de sua própria dissolução como sujeito: a vela não se fixa, firmemente, à cadeira de balanço, onde ocupa uma posição meio hesitante, quando não chocante. Mais ainda, diz Bataille, com relação ao lampião, a tal vela se apresenta como que humilhada, tal como o cachimbo frente à luz do lampião, o que só acentua "el signo de la heterogeneidad irreductible de los elementos desgarrados (y desencadenados) de la persona de Vincent van Gogh" [19]. Dessa peculiaridade que liga imagem e morte deriva, em última análise, uma das obras mais emblemáticas de Bataille, As lágrimas de Eros. Se bem se vê, em todos esses casos, estamos perante imagens de acefalia.

Mas, neste ponto, seria bom relembrar que essa disseminação de experiências e leituras coincide com a idéia do corps morcelé, que levará Lacan a falar de três registros, o imaginário, o simbólico e o real, equiparados en hierarquia. Caberia acrescentar a isto que um dos críticos mais atentos às profanações lacanianas, Roland Barthes, irá precisamente extrair dessa tradição sua teoria da imagem como punctum, isto é, como vazio, como neutro.

Há a esse respeito um livro híbrido, $A$ invenção do finito de Murilo Mendes, que recolhe um conjunto igualmente heterogêneo de textos, sobre artistas de seu convívio europeu, escrito ao longo dos anos 60, livro esse que o poeta dedicou a Mário Pedrosa, "crítico criador" e "companheiro de arte", muito embora a confiança no moderno de Pedrosa, bom leitor de Greenberg, nem sempre coincida com o experimentalismo pós-modernista de Murilo Mendes. Mas, em todo caso, como já tive ocasião de assinalar, a versão original de $A$ invenção do finito traz, após a dedicatória, uma citação de Roland Barthes muito significativa. É uma citação, que consta do original datilografado, com uma nota apensa, manuscrita pelo próprio Murilo que diz: "Esta citação deverá ser inserida entre a página do título e a do texto". A citação, de fato, diz:

Je ne peux que faire mienne la pensée de Lacan: ce n'est pas l'homme qui constitue le symbolique, mais c'est le symbolique qui constitue I'homme. Quand I'homme entre dans le monde, il entre dans le symbolique qui est déjà là.

Roland Barthes.

O signo entre é aqui todo um sintoma que não só podemos mas até devemos ler em plus d'une langue. Com efeito, entre o título e o texto, a citação ela entre dans le monde, ou melhor, ela entre dans le symbolique qui est déjà là. E esse symbolique qui est déjà là é, prioritariamente, uma fala de Barthes que se coloca entre uma e outra instância. A fala de Barthes, sua reflexão sobre a imagem e a letra, sobre o imaginário e o simbólico, situa-se, portanto, entre o privado e o público, entre o sagrado e o profano. Entre as palavras e as coisas, como dirá o mesmo autor no Sistema da moda, ou entre o prazer do texto e a utopia do pensamento [20]. Essa indecidibilidade será desenvolvida, como sabemos, em $A$ câmara clara.

Ce que la Photographie reproduit à l'infini n’a eu lieu qu'une fois: elle répète mécaniquement ce qui ne pourra jamais plus se répéter existentiellement. En elle, l'événement ne se dépasse jamais vers autre chose: elle ramène toujours le corpus dont j'ai besoin au corps que je vois: 
Vou me deter em dois conceitos de clara extração bataillana. Bête, animal, e souveraine, soberana, um atributo da imanência. O primeiro alude ao grupo acefálico reunido em torno de Bataille, que publicava a revista Minotaure la revue à tête de bête. Desse grupo fazia parte Lacan, que, nessa revista, divulgou sua teoria da paranóia, elaborada a quatro mãos com Salvador Dali, o mesmo Dali que espetaculariza sua fantasia escópica de $O$ cão andaluz (1928) na famosa cena de Spellbound (1945), o filme de Hitchcock. O mesmo Dali que foi sondado pelos estudios Disney e que, por pouco, com o filme Destino (2003), quase se torna o narrador de massas contemporâneo.

Mas quero ainda chamar a atenção de vocês para o conceito de soberania. Antes de mais nada, para o paradoxo barthesiano de uma contingence souveraine. Mas, basicamente, gostaria de destacar que a soberania é uma fantasia. Ex nihilo summum [21]. A soberania é o fantasma da summa potestas, da potência absoluta sem nenhuma autoridade por cima dela. Superanus, donde deriva souveraine, qualifica assim a onipotência divina e, em consequência, a superioridade do rei por direito divino. Derrida chamou esse conceito de principe-phantasme archaïque [22] já que a soberania é um princípio sempre ligado à lógica da arché. Menos do que aludir, na sociedade contemporânea, a um caráter espectral da soberania, condição para a qual Derrida reserva vários outros termos (fantôme, spectre, revenant), no conceito de soberania como fantasme, Derrida remeteria à ilusão autárquica, à pulsão de autoposição da ipsidade, presente nesse conceito, a ponto que um filósofo italiano, Simone Regazzoni, associa o conceito de soberania à Phantasie freudiana. Explica, assim, que

il fantasme si distingue dal fantôme e dallo spectre in quanto opera come uno strumento di difesa contro l'elemento inassimilabile che destabilizza l'autoposizione pura dell'ipseità. Il fantasme resiste all'elemento inassimilabile che lo minaccia e che, precisamente, nella sua restanza senza consistenza, resiste all'appropriazione. Il principio fantasma della sovranità è un fantasma di onnipotenza che si erige al di sopra di tutto, un fantasma di autodeterminazione assoluta di sé (che al fondo resta sempre impossibile, non si dà mai nella sua purezza) che non tollera nessuna limitazione esterna. E questo potere fantasmatico è da sempre un potere dai tratti virili, circondato e rappresentato da simboli virili. [23]

Outro crítico, Michael O'Rourke, completa a observação assinalando que, na reflexão de Derrida, jamais se alude ao caráter fálico dessa conceituação de poder superanus e, em particular, não se menciona a atração (anal) que Derrida demonstraria pelos escritos de Bataille [24].

Isto posto, retomemos a caracterização barthesiana da fotografia: ela reproduz à l'infini aquilo que só teve lugar uma vez: ela repete mecanicamente aquilo que jamais se poderá repetir existencialmente, de sorte que 0 evento não se derrama, não deriva, não foge em direção a outra coisa. A imagem é centrípeta. Ela joga le corpus dont j'ai besoin, o corpus de que preciso, em direção ao corpo que vejo, le corps que je vois. Memória na percepção, eis o segredo da imagem. Donde a imagem fotográfica torna-se o Particular absoluto ou a Contingência soberana, a que Barthes passa a chamar le Tel (telle photo, et non la Photo) com um conceito que ele extrai, aliás, dos seminários de Lacan, o conceito de Tuché, o reencontro com o Real. O mesmo Barthes associa o conceito de Real com um termo budista, sunya, o vazio; ou ainda, tathata, o fato de ser tal, de ser assim, de ser isto; porque tat, em sânscrito, quer dizer isto e lembra o gesto dêictico, Ta, Da, Sa!

Portanto, enquadrada nesse marco, a teoria da fotografia ressignifica-se como uma reflexão sobre o entre, sobre o neutro ou, mais especificamente, sobre a morte. O punctum da imagem revela sempre a pungência do real. È decisiva, nesse ponto, a contribuição de Michel Leiris, não só a respeito do caráter especular da posição do etnógrafo, mas acerca do sentido como caput mortuum da experiência, expressão alquimista que significa resíduo impossível de absorver e que estimulará Lacan a elaborar sua teoria do objeto petit a [25]. Seja lá como for, é inegável que, sem sombra de dúvida e apesar dos pesares, estamos sempre lidando com imagens, mas estamos também lidando com o tempo [26]. Um tempo que bem pode não ter história. Ernesto Laclau, retomando o conceito hegeliano de povos sem história, diz que essa presença não-histórica absolutamente contingente desborda a dialética da história, tornada ela mesma, por esse ato, contingente, e assimila o conceito ao caput mortuum de Lacan [27]. E é, finalmente, desse punto de la nada, que Agamben também vai resgatar a noção de imagem como phantasmata, ou seja, como um hiato ou vazio temporal que define, em última instância, os movimentos da história como criações de sobre-natureza.

Mas tudo isso já está, com efeito, em Bataille. Em uma versão abandonada de A Parte maldita, Georges Bataille aborda, precisamente, esse abismo conceitual que, mais tarde, Agamben chamaria o reino e a glória. Lemos:

El abuso que los mexicanos hacían de la muerte nos sitúa ante un abismo. Un abismo al que sin duda seguiremos acercándonos siempre, atraídos por el horror, pero de momento quiero apartarme de él y no considerar más que la gloria, que era lo único que los mexicanos perseguían Los mexicanos no perecían en su propio abismo. En rigor podría decirse que a la llegada de Cortés, México se hundió, pero eso sólo llegó a suceder un día. México vivió hasta el final ebrio de gloria. Pero no como en nuestros días: entonces una verdadera tragedia y un sentimiento de ironía aparecían fuertemente mezclados. Para un mexicano la gloria no estaba relegada, como para nosotros, no era una cosa aparte de la vida cotidiana. No era ni ostentosa ni superficial. Muchos de nosotros vemos en la gloria algo superfluo, una futilidad. Un mexicano vivía poseído por ella del mismo modo que poseemos piernas (sin más historias), era algo que no se discutía y de donde provenía ese sentimiento de profunda ironía respecto a la vida humana (e incluso respecto a los dioses). La gloria era la única medida: estaba por encima de cualquier otra posibilidad y además hacía girar todo en torno a ella. El tumulto de las fiestas, lo mismo que el de las guerras, tenía un eficaz poder, análogo al de un corazón que late. Ponía al hombre y a cada uno de sus actos -incluso el más humilde- a la altura del Universo. Esta armonía animaba y fecundaba los trabajos del campo. El sentido mismo de las cosechas se expresaba en las danzas y los sacrificios. Los aztecas, lo mismo que otros pueblos primitivos, se equivocaban al conceder a sus ritos un poder análogo al de los trabajos agrícolas; no obstante su vida y sus cosechas estaban efectivamente relacionadas con los esplendores del cielo. Nada más lógico que atribuir fines espléndidos a la actividad económica: el reino de la pura necesidad es más profundamente hostil a la vida que el horror (...). Los sacrificios ponían en armonía al hombre con el universo. La fe en la eficacia de los ritos estaba en su base pero bastó para justificarlos con invertir el sentido: los mexicanos no podían hacer que la naturaleza les siguiese pero vivían de acuerdo con la naturaleza [28].

Mas não nos esqueçamos que, entre Bataille e Agamben, está Guy Debord. Em $A$ sociedade do espetáculo, Debord postula que, conforme aumentavam o comércio e a acumulação de capitais, a mercadoria passou a assumir o domínio absoluto da economia, o que transfigurou o trabalho humano em trabalho-mercadoria e produziu tamanha abundância que a questão da sobrevivência passou a ficar resolvida, mesmo que resolvida de um modo que fazia com que ela tornasse sempre a aparecer como problema. O crescimento econômico liberava as sociedades da pressão natural, que exigia sua luta imediata pela sobrevivência; mas, agora, diz Debord, é do libertador que elas não conseguem se liberar. A economia (a autonomia) transformou o mundo, mas o transformou apenas em mundo da economia. A conclusão é clara: na sociedade do espetáculo, a imagem é a própria sobre-natureza [29]. Ela dita assim o regime pós-significante ou pós-autonômico.

O modernismo organizou seu sistema axiológico em torno da tensão dialética entre o alto e o baixo, o ativo e o passivo. Bataille, pelo contrário, em suas pesquisas meta-antropológicas, ensaiou um outro regime de leitura. Associou, por exemplo, o Quetzalcoatl a uma figura de histórias em quadrinhos dos anos 30, os Pieds nickelés. Bataille, com efeito, lia essas imagens em obediência ao anacronismo dessas figuras que ele vinculava a uma palavra desprovida de sentido, uma palavra ainda sem língua, uma experiência dadá. Argumentava assim que "si otorgamos al entretenimiento un sentido suficientemente mejicano, es decir una intervención siempre más o menos extemporánea en los domínios más serios, el entretenimiento todavía puede parecer como la única reducción del idealismo" [30]. Nesse procedimento proposto por Bataille reconheço o gesto fundacional de uma crítica que admite uma participação temporal na temporalidade, ou seja, uma hiper-temporalização, infinita e potencializada, do evento singular irradiante. 
Gostaria de ilustrar essa questão com um percurso extremamente singular e cindido, o da dupla Horacio Coppola Grete Stern. O fotógrafo argentino acompanha, em 1929, as conferências de Le Corbusier em Amigos da Arte, o primeiro salão modernista de Buenos Aires. Notadamente impressiona-o uma palestra em que Le Corbusier analisa "La mirada de las casas tradicionales de Buenos Aires como formas abstractas". Essa questão tornar-se-ia o eixo em torno do qual Coppola passaria a construir sua obra em torno das metamorfoses dos bairros da cidade. Tirava proveito, em seus ousados framings, das perspectivas e dos pontos de fuga, enfatizando as linhas e os ângulos geométricos das fachadas, passeios e terraços da cidade planejada. Sua fotografia "Homenagem a Juan Gris", recentemente resgatada, como epígrafe à exposição "El cubismo y sus entornos en la colección Telefónica" (Buenos Aires, Museu de Belas Artes, 2008), fotografia que, até hoje, pende da cabeceira do fotógrafo centenário, é um bom exemplo disso. Nessa mesma época, final dos anos 20, em parte estimulado pelos filmes surrealistas que o artista franco-romeno Benjamin Fondane exibe em Amigos da Arte, Coppola funda, com Leon Klimovsky, o primeiro Cine Clube argentino, de que foi, aliás, diretor-fundador. Entra em contato, a partir da viagem a Europa, em 1930, tanto com a obra do artista húngaro Laszlo Moholi-Nagy, quanto com as experiências do fotógrafo alemão que orientava o grupo da Nova Objetividade, Albert Renger-Pätzsch, experiências ambas que redirecionam sua estética. Capta, assim, nas fotografias européias tiradas nos anos 30, a metamorfose da matéria, tal como nas grades curvilíneas das sacadas da prefeitura de São Gimignano.

Em 1932, Coppola regressa à Alemanha, estuda na Bauhaus berlinesa, com Walter Peterhans, e aí conhece uma jovem fotógrafa, Grete Stern, com quem logo mais se casaria. Coppola percorre então a Europa e viaja, entre outros destinos, a Paris, onde Christian Zervos, o diretor de Cahiers d'Art, com quem estabelece contato graças ao historiador José Luis Romero, encomenda-Ihe seu primeiro livro fotográfico: L'Art de la Mésopotamie. Fotografa, para tanto, o acervo de arte suméria do Louvre e do British Museum. O escultor Henry Moore, que frequentava o museu estudando essas peças desde o início dos anos 20, resenha a obra, em uma extensa análise, na revista The Listener. Não teme sobre-estimar as fotos e admite elas aumentarem o interesse que sentia pelas obras originais [31]. É a época, diga-se de passagem, em que Moore, muito marcado também pelas idéias de Roger Fry, em Vision and Design (1920), trabalha em sua escultura Girl with clasped hands, de evidentes ecos sumérios, e em diálogo aberto com as figuras de Picasso.

Através de Zervos, ainda, Coppola passa a frequentar as oficinas de Marc Chagall e de Joan Miró, cujos retratos publica em Paris. Ensaia vários films, como Traum (1933) e documentários cinematográficos sobre a região de La Ardéche, entre Lyon e Marseille, e filma, em Londres, Um domingo em Hampstead Heath (1935). Retorna a Buenos Aires, em função da morte do pai, para assumir as empresas da família. "Victoria Ocampo nos ofrece la redacción de Sur para la primera exposición conjunta que realizamos con Grete", e logo mais, o prefeito Mariano de Vedia y Mitre encomenda-lhe um volume em homenagem ao IV Centenário da cidade, Buenos Aires, 1936. Visión fotográfica, que muito contribuiu para a memória visual mítica da fotografia urbana, tal como o Paris de nuit de Brassaï; o Stockholm, de Andreas Feininger ou os perfis londrinos de Bill Brandt. Desse período há, ainda, um filme, Así nació el obelisco, sobre a construção desse monumento, marco do IV centenário de Buenos Aires e verdadeiro principe-phantasme archaïque, uma vez que, símbolo funerário, o obelisco lembra a arkhé da cidade, que não é outra coisa que um repasto totêmico. Destruida em 1536, Buenos Aires precisou ser fundada uma segunda vez, em 1580. O obelisco, portanto, relembra um nascimento que a rigor é uma carnificina. Não por acaso ele constará da foto de família do grupo concreto-abstracionista Ma-di, fotografia composta por Grete Stern, quem reuniu o grupo, pela primeira vez, em sua casa de Ramos Mejía.

Em 1937, junto a Luis Baudizzone, advogado e escritor, amigo de artistas, Horacio Coppola funda a editora de la Llanura. Pouco depois, em 1942, certamente estimulado pelos textos de Mário de Andrade e do amigo comum, Newton Freitas, então instalado em Buenos Aires, Coppola já não se sente inclinado a documentar tão somente o fantasma da summa potestas, o obelisco-falo da autonomia nacional e periférica, que conota, sem dúvida, uma ilusão autárquica, a autoposição da ipsidade. Ensaia, muito pelo contrário, um exercício fotográfico para captar a contingência absoluta, o poder tornado ruína da modernidade. Parte, portanto, a seguir, em 1945, com o apoio do SPHAN, à aventura de documentar a obra de Aleijadinho, que embora sem maior documentação no Brasil, certamente não era desconhecida na Argentina. Pensemos que, já em 1931, o arquiteto Angel Guido, um dos teóricos do neocolonial, escreve sobre Aleijadinho no jornal La Prensa, artigo logo retomado, em inglês, pelo Boletim da União Pan-americana e que, em 1939, outro arquiteto, Mario José Buschiazzo, publicaria um volume sobre o artista barroco de Minas. Em carta a Victoria Ocampo, André Malraux julgou as fotos de Aleijadinho, tiradas por Coppola, magníficas, completando esplendidamente seu Museu imaginário.

Todavia, a exposição de barroco mineiro sonhada por Coppola para suas fotografias mineiras não contou com apoios à época e as imagens demorariam inéditas até 1955, quando seriam publicadas pela editora de la Llanura, em associação com o artista gráfico Luis Seoane, bastante atraído pela arte indo-americano, quem ilustra a capa com uma gravura, e o poeta Lorenzo Varela, com um poema-prólogo, artistas republicanos espanhóis que, com outro galego, Arturo Cuadrado, fundariam por esses mesmos anos uma pequena editora de poesia, Botella al Mar, nome de uma das fotomontagens de Grete Stern.

Não esqueci, nos meandros das imagens de Coppola, de sua mulher, Grete Stern. Após as experiências dadaístas e Bauhaus, em que realiza autênticas naturezas mortas fotográficas, muitas delas com Ellen Auerbach, Grete passa a dedicar-se ao retrato. São dessa época as fotos de Borges e do já citado Newton Freitas, tiradas em Buenos Aires, ou as do périplo europeu, quando registra, entre outros, a Bertold Brecht. Ainda em 1943, Grete Stern e Horacio Coppola fotografam o que seria o último trabalho conjunto, já que se divorciam nesse ano. Trata-se de uma série de huacos, vasos antropomórficos da cultura Chimu, que os obrigam a declarar essas imagens como pertencentes a um gênero híbrido, vasos retratos, onde convergem as heterogeneidades de ambas as trajetórias (Huacos. Cultura Chimu. Buenos Aires, Ediciones de la Llanura, 1943). O pintor Antonio Berni escrevia na ocasião:

Los huacos-retratos de la cerámica antigua del Perú no han sido estudiados, sentidos $y$ valorados en lo que tienen de más interesante: el de ser una de las bellas manifestaciones del arte escultórico que ha realizado el hombre. Nuestros museos de Bellas Artes han puesto poco interés en incorporar al acerbo artístico de sus colecciones el inmenso caudal del arte americano que -desde el preincaico, pasando por la colonia, hasta fines del siglo pasado forman un legado que podría ser orgullo de cualquier nación del mundo. Los huacos-retratos son, por ahora, curiosidades de los museos arqueológicos, etnográficos o históricos, como caso extraordinario de cultura aborigen, pero estas obras rebasan, por ellas mismas, los límites del común fenómeno arqueológico para entrar, con todos los honores, en el vasto conjunto de las grandes creaciones artísticas de la humanidad [32]

Luis Seoane ensaiaria também alguns vasos-retratos, em cerâmica de Sarzadelos, deles se destacando o que tem a cabeça de Unamuno. Punto de la nada. A idéia nos chama a atenção para o duplo vazio dos huacos-retratos. Os huacos são o primeiro significante modelado pelo homem, mas eles não são significantes em sua essência de vasos, ou seja, eles não valem como equivalentes de algo já particularmente significado. Porque os huacos são huecos criam o vazio ao redor deles, introduzindo, portanto, na cultura, fazendo com que il entre dans le symbolique, a perspectiva de seu preenchimento. Como diz Lacan no seminário sobre a Ética, o vazio e o pleno se introduzem, através do vaso, através do huaco, em um mundo que, por si mesmo, não conhece previamente nada parecido com aquilo.

Heidegger, analisando também a lógica do vaso, afirmaria que o huaco era conduzido a sua condição ontológica, em cumprimento da aletheia, através da retenção, reunião e manifestação da verdade. Porém, o vaso adquire, para Heidegger, uma função significante só quando ele se depara com sua função utilitária. Lacan, entretanto, opõe o caráter utilitário a uma nova função, se assim podemos falar, sem nome, sem lei, acéfala, a função significante, pelo simples motivo de que é ela que faz com que um simples vaso se torne um huaco. Em poucas palavras, para Lacan, um significante não significa o ser em sua verdade essencial, ele não significa nada em particular, a não ser o próprio ser como nada, como vazio. Em suma, para Lacan, o huaco significa, sendo que aí o verbo significar é meramente intransitivo. Isso quer dizer que, de um lado, rechaça-se a problemática da origem mas, de outro, essa questão não deixa de ser uma potencialização dessa arkhé impossível. O novo significante do huaco, da fotografia do huaco, mais do que introduzir o uso (etnográfico), no discurso crítico, ele introduz, como queria Berni, o vazio (estético), o ser da significância, na cultura e, nesse sentido, ao ser modelado à semelhança da Coisa, o huaco dá consistência aquilo que é impossível de imaginar, a arkhé, a própria cultura, o sentido. As fotografias dos huacos-retratos não deixam de ser, assim raciocinando, autênticas instalações madi: elas são o retrato da Coisa.

Por outro lado, enquanto retratos, os huacos-retratos questionam a lógica do modelo civil, porque, como sabemos, os retratos nascem, no Ocidente, vinculados ao estado civil do retratado, à sua passagem de um estado a outro, da infância à adolescência, seu casamento, seu apogeu como personagem pública. Jean-Luc Nancy argumenta, entretanto, que o estado civil do retrato é seu estado figural porque, quando o retrato dá preeminência ao estado civil, a identidade dos protagonistas encontra-se, a rigor, fora do quadro, fora de cena. Torna-se obscena. Ė puro vazio de representação. Mais ainda: o retrato é ele mesmo seu próprio estado civil, já que ele põe em jogo sua própria civilidade ou sociabilidade e só nela, e graças a ela, os sujeitos entram numa relação social, enquanto sujeitos e não enquanto objetos [33]. Vemos, portanto, que, seja como 
huacos, seja como retratos, essas imagens dos huacos-retratos nos revelam o tratamento da Coisa como semblante.

Ora, pouco depois das fotos desses vasos-retratos, Grete Stern começaria uma experiência inquietante, onde efígie e morte, tal como nos Huacos, mais uma vez, tornam a aparecer. Na revista de massas Idílio ela passa a ilustrar uma coluna chamada "El psicoanálisis le ayudará" [34]. A lógica compositiva era relativamente simples: as leitoras de Idílio narravam, em cartas à redação, seus sonhos, seus pesadelos, suas ansiedades. Um cientista social, Richard Rest, interpretava esses sonhos anônimos, porém, coletivos. Rest era, a rigor, o pseudônimo por trás do qual se ocultava o sociólogo italiano Gino Germani, mais tarde famoso por suas idéias a respeito da modernização na América Latina [35]. Grete Stern, a partir desses relatos anônimos, compunha fotomontagens, uma técnica dadaísta que a imprensa periódica argentina já explorara, aliás, com fins satíricos, em Caras y caretas, e com fins decorativos, em Viva cien años. Essas fotomontagens de Stern são, entretanto, a primeira e mais contundente expressão de certas imagens do pensamento que denunciam, de forma pioneira, a opressão e o servilismo da mulher na sociedade argentina, porém, o fazem com os códigos dessa mesma gramática feminina de massas, não muito distante, portanto, dos sonhos de evasão dos filmes sentimentais ou de revistas como Radiolandia [36]. Nesse sentido, as imagens do pensamento de Grete devem ser lidas com as ficções de Manuel Puig. Afinal, as leitoras de Idílio são as heroínas de Puig.

Luis Príamo destaca que Grete soube tirar proveito, a partir da lição oferecida pelas fotonovelas, também estampadas pela revista Idilio, da pungência de uma relativa neutralidade que rebaixasse o pathos. Toca assim os tópicos de Barthes: o punctum, o neutro:

Grete realizó todos los trabajos para Idilio con una convención básica: el personaje del sueño, esto es la propia soñadora, siempre esta presente en la imagen, ya sea de un modo explícito o implícito. En el primer caso -el más frecuente- la vemos participando de la situación ilustrada, como si fuera una instantánea del sueno en desarrollo; en el segundo, la cámara asume el lugar de su mirada, produciendo lo que en cine se llama una toma subjetiva. Este último procedimiento introduce una variante formal sugerente. Las subjetivas son naturalmente elípticas, ya que no ilustran una peripecia, sino las consecuencias de un sentimiento traducidas en visión, con lo cual las composiciones abandonan la anécdota y proponen al espectador una participación más activa, ya que debe mirar con los ojos de la protagonista del sueño y proyectar imaginariamente sus sentimientos. En los sueños de celos, por ejemplo, el estupendo primer plano no solo instala al espectador en la perspectiva de intimidad de la protagonista con el hombre de la foto, y lo hace partícipe de la evidencia de adulterio que ella ve reflejada en sus anteojos, sino que lo fuerza a proyectar en esos bigotitos engolados, en el cigarrillo sobrador que cuelga de sus labios y en la sonrisa cínica, la petulancia fatua del seductor profesional, del Tyrone Power criollo según la moda de los anos cincuenta... La utilización de los anteojos, dicho sea de paso, fue un hallazgo brillante, ya que no solo le permitió a Grete aplicar los retratos de las mujeres con un encuadre perfecto, sino que agrego un matiz de simulación, de enmascaramiento que hace más desagradable al personaje de la foto.

Estos fotomontajes subjetivos evitan uno de los problemas de verosimilitud más frecuentes en el conjunto mayor de la serie, donde el personaje que sueña está en cuadro y representa dramáticamente su peripecia. Las expresiones de miedo, pasmo, felicidad o desconcierto son congruentes con lo que experimenta el personaje; sin embargo, la ficción de estados de animo representados con gesticulación enfática, simulando una instantánea del momento álgido del episodio dramático, conspira contra la verosimilitud de la imagen. Esto lo sabían bien los directores de las fotonovelas que la revista Idilio editaba simultáneamente con los Sueños. Allí los actores nunca representan sus estados anímicos en el momento expresivo de mayor intensidad, sino que asumen gestos más bien neutros, expresiones contenidas, de modo que el lector proyecte sobre sus rostros los sentimientos que adivina o presume. La imagen fotográfica es "demasiado" verosímil como para soportar ficción suplementaria: sistemáticamente la denuncia como falsa. En general, esto sucede también con los fotomontajes de Grete, donde la mayor eficacia se consigue cuando la expresión del personaje es más bien neutra, de modo que el efecto se produce no por empatía, sino por el choque de los elementos que forman la imagen, contrapuestos o discordantes [37].

As fotomontagens de Stern funcionam, de fato, como a resposta de uma cultura de transição, na falta de melhor rótulo, populista, ao estilo autônomo e letrado do primeiro modernismo. Mas são também, simultaneamente, o canto do cisne da autonomia, são uma friç̧ão do Real. Elas ativam o mesmo pressuposto que Derrida desenvolve em Droit de regards, a fotografia não pode, a bem da verdade, deixar de domesticar o referente, mas pode muito bem afastar infinitamente 0 referente perceptível [38]. Blanchot, a esse propósito, evocaria a máscara mortuária como sombra que vai além do valor de uso, tal como queriam os surrealistas de Documents, fazendo com que a imagem tivesse o valor de uso do impossível, e Barthes, finalmente, chegaria mesmo a sugerir algo semelhante quando, em $A$ câmara clara, diz que a fotografia é uma image folle, frotée de réel. Em todo caso, a fricção da imagem com o Outro do referente aponta sempre à sua negatividade, a seu espectro, à sua dispersão.

Essas fotomontagens, portanto, mostram que os circuitos letrados, os dos amigos da arte, como Coppola ou Le Corbusier, ou os dos companheiros de arte, como diz Murilo de Pedrosa, já não bastam, a essas alturas, para manter o vínculo tradicional humanista. As comunidades tornaram-se inoperantes. Sob diversas perspectivas, no fundo, convergentes, Michel Foucault, Giorgio Agamben, Roberto Espósito ou Peter Sloterdijk têm assinalado, nesse ponto, o declínio da vida enquanto bios e o reino da vida como zoé, vida acéfala para a qual contamos apenas com parques zoológicos imateriais, cada vez mais eficientes [39]. As fotografias de Grete tiradas no Chaco são um exemplo eloqüente disso.

Disse, no início, que as imagens não são fatos. Tentei, nesta apresentação, pensar por imagens. A meu ver, as condições de possibilidade da autonomia já não bastam para pensar o contemporâneo porque, no cenário pós-autonômico em que nos encontramos, já não se debatem formas senão forças. Essas forças, a que chamamos também de imagens, são enigmas, em que, da superposição de elementos dissímeis, tais como o arcaico e o atual, a tradição e a ruptura, o trágico e o farsesco, o arquipassado e o ainda por-vir, surge, com todo seu magma, com toda sua complexidade, o contemporâneo. Nesse caráter híbrido e cindido, onde se encavalgam Henry Moore e a arte suméria, Coppola e Brassaï, Berni e o Aleijadinho, o peronismo e a psicanálise, Madi e Heidegger, Bataille e Lacan, o espaço da repetição, ou seja, o eterno retorno de certas imagens, já não se explica através da lógica da representação e demanda, no entanto, a da repetição. E quem diz repetição, diz inconsciente.

O movimento das imagens, na cena contemporânea, não comporta, com efeito, um marco formal de circulação global, mas exige analisar o modo em que, sob esse regime, os corpos, a vida, são atualmente produzidos, reproduzidos, lançados ou, a rigor, abandonados. Uma parte do real persiste, apesar de todos os esforços de sublimação, na ordem simbólica, quer dizer que algo, em nossa leitura da história cultural, está mesmo sempre presente, enquanto ausência, e esse algo chama-se, para Lacan, agalma, a Coisa, das Ding, excesso de gozo, desejo do Outro, objeto causa do desejo, objet petit a. $\mathrm{E}$, para Debord, ele é o surplus de survie, em outras palavras, o punctum da imagem é que sustenta a sociedade do espetáculo. Ausente no mundo da presença material, esse resto ou caput mortuum é um vazio estrutural, ou centro gravitacional, em torno do qual funciona, a rigor, a ordem simbólica [40]. Mas o caput mortuum nos revela, ainda, a superposição (com) de vários tempos, a primeira vista, desconexos.

A esse respeito, em 1955, em sua análise de "A carta roubada", Lacan retoma um escrito bastante anterior, de 1945, "O tempo lógico e a afirmativa da certeza antecipada", que, como disse, foi publicado em Cahiers d'Art, a revista de Zervos, e nos mostra que, no relato de Poe, superpõe-se três tempos não sincrônicos. Há, assim, o momento do olhar (em que o Ministro repara que o rei não enxerga a carta apoiada na lareira), há o tempo da compreensão (em que o Ministro adverte que a rainha observa a carta e vê, ainda, que o rei não a vê) e há o momento da decisão (em que o Ministro oculta a carta, sob o olhar da rainha que nada pode fazer, sob pena de atrair o olhar do rei sobre a carta). E, na cena repetida, esses três tempos se repetem, mais uma vez, de maneira quase idêntica, se substituirmos o rei pelo policial, a rainha pelo Ministro e o Ministro pelo detetive Dupin. A única, porém, que permanece no lugar cativo é a carta, caput mortuum da cena do desejo. É a persistência do significante, então, aquilo que Ihe permite a Lacan postular, na cena, um automatismo de repetição, cujo sentido se confirma pelo acaso do contemporâneo, ou seja, "I'actualité qui a dans son présent, le futur antérieur. Que dans I'intervalle de ce passé qu'il est déjà à ce qu'il projette, um trou s'ouvre qui constitue um certain caput mortuum du signifiant" [41]. Esse trou que se abre nos objetos contemplados numa imagem-esse huaco, esse retrato-não é, como vemos, o retrato de um indivíduo mas o retrato da morte do sentido já constituído. É o caput mortuum do significante. Esse significante que só significa 
para outro significante mas que, em todo caso, decreta a morte do objeto. Creio que é sob essa perspectiva que podemos ler, anacronicamente, as imagens de Coppola-Stern como uma ficção sem autor, uma fulguração sem exterior, uma passagem instantânea do orgânico ao inorgânico, uma basculação entre obra e texto e um abandono da ação em favor da inoperância.

Recebido em 13/10/2008. Aprovado em 10/11/2008

Resumos

Title: Images as force

Author: Raul Antelo

Abstract: Assuming that images are forces and not facts or forms, the present essay elaborates a theory of photography as the decline of the sense, pursuing the relations between the contemporary and the image in Oswald de Andrade's anthropophagy, in Marcel Mauss, Alfred Métraux, Georges Bataille, Murilo Mendes, Roland Barthes, etc. Next, the trajectory is retraced of photographers Horacio Coppola and Grete Stern, in order to illustrate a procedure that deviates from autonomic and lettered modernism, reading their work as a fiction without an author, a fulguration with no exterior, an instant passage from the organic to the inorganic, a mixing between work and text and an abandonment of action in favor of inoperativeness. Keywords: image, photography, Modernism.

Tìtre: Les images comme force

Auteur: Raul Antelo

Résumé: A partir de l'idée selon laquelle les images sont des forces et non des faits ou des formes, l'essai élabore une théorie de la photographie en tant que déclin du sens au même temps que poursuit les rélations entre le contemporain et l'image dans l'antropophagie de Oswald de Andrade, en Marcel Mauss, Alfred Métraux, Georges Bataille, Murilo Mendes, Roland Barthes etc. Ensuite, refait le parcours des photographes Horacio Coppola et Grete Stern pour ilustrer une procédure qui s'écarte du modernisme autonomique et léttré, en lisant leurs travaux comme une fiction sans auteur, une fulguration sans extérieur, un passage instantané de l'organique à l'inorganique, une basculation entre oeuvre et texte et un abandon de l'action en faveur de l'inaction.

Mots-clés: image, photographie, modernisme.

Título: Las imágenes como fuerza

Autor: Raul Antelo

Resumen: A partir de la idea de que las imágenes son fuerzas y no hechos o formas, el ensayo elabora una teoría de la fotografía como el ocaso del sentido que persigue las relaciones entre el contemporáneo y la imagen en la antropofagia de Oswald de Andrade, en Marcel Mauss, Alfred Métraux, Georges Bataille, Murilo Mendes, Roland Barthes etc. Posteriormente, se rehace el precurso de los fotógrafos Horacio Coppola y Grete Stern para ilustrar un procedimiento que se desvía del modernismo autonómico y letrado, leyendo sus trabajos como una ficción sin autor, una fulguración sin exterior, un pasaje instantáneo del orgánico al inorgánico, una bascula entre obra y texto y un abandono de la acción a favor de la inoperancia.

Palabras-clave: imagen, fotografía, modernismo.

\section{Notas}

[*] Graduado em Letras Modernas pela Universidade de Buenos Aires e em Língua Portuguesa pelo Instituto Superior del Profesorado en Lenguas Vivas. Mestrado e Doutorado em Literatura Brasileira pela Universidade de São Paulo. Atualmente, é professor titular da Universidade Federal de Santa Catarina.

[1] Cf. AGAMBEN, Giorgio - Che cos 'è un dispositivo? Roma, nottetempo, 2006.

[2] Cf. APPADURAI, Arjun - La modernidad desbordada: dimensiones culturales de la globalización. Buenos Aires, Trilce, 2001.

[3] FOUCAULT, Michel - "Theatrum philosophicum"in Dits et écrits.Paris, Gallimard, 1994, vol. II.

[4] Franco Rella diz "le immagini non sono fatti" e logo a seguir pergunta-se: "Ma abbiamo idea delle sue immagini? Abbiamo noi immagini attraverso cui leggere in questo anche frammentariamente una qualche storia o un qualche senso?" Cf. RELLA, Franco - Pensare per figure. Freud, Platone, Kafka il postumano. Roma, Fazi, 2004,p.138.

[5] Cf. AGAMBEN, Giorgio - Ninfe. Torino, Bollati Boringhieri, 2007. Ver también, del mismo autor, Image et mémoire. Trad. Marco Dell'Omodarme et al. Paris, Hoëbeke, 1998

[6] IDEM- Signatura rerum. Sul metodo. Torino, Bollati Boringhieri, 2008, p.31.

[7] IDEM - "Identificación y desidentificación de un autor llamado José Bergamin", Archipélago. Cuadernos de crítica de la cultura. no 46, abr.-maio 2001, p.87.

[8] IDEM - Profanazioni. Roma, Nottetempo, 2005, p.71

[9] Cf. DERRIDA, Jacques - "Mes chances. Au rendez-vous de quelques stéréophonies épicuriennes" in Psyché, inventions de l'autre. Paris, Galilée, 1987.

[10] Cf HEIDEGGER, Martin - Beiträge. Frankfuert, Klostermann, p. 268 e NANCY, Jean-Luc - Un pensamiento finito. Trad. J. C. Moreno Romo. Barcelona, Anthropos, 2002, p.9.

[11] Cf. NANCY, Jean-Luc - La creación del mundo o la mundialización. Trad.P. Velamazán. Barcelona, Paidós, 2003, p.82-3

[12] Cf. BATAILLE, Georges. "El arte, ejercicio de crueldad" in La felicidad, el erotismo y la literatura. Ensayos 1944-1961. Selección, traducción y prólogo de Silvio Matoni. Buenos Aires: Adriana Hidalgo, 2001, p.117

[13] Em "La des-obra como ready-made" aponto uma das tendências da crítica do presente: o comentário. "La interpretación trabaja con el sentido, pero con un sentido dado, intencionado, original, histórico, adecuado o auténtico. Busca fijarlo, agotarlo. Quien comenta, en cambio, quiere promover la integración de contextos culturales antagónicos, anacrónicos o distópicos, a los cuales les ofrece un puente, un vinculo, un suplemento. El comentario depende, sin duda, de la interpretación, está subordinado a ella, pero alli donde la interpretacion concluye, el comentario inconcluye. El comentario no se puede callar: Lo suyo, como diria Jabès, es comment-taire. Hay, por tanto, una tarea finita de la interpretación y una tarea infinita del comentario. La topología de la interpretación busca jerarquizar entre lo visible y lo invisible. El comentario, sin embargo, no persigue nada más allá, más atrás o subyacente a los hechos mismos. Es lateral. Se ofrece como para-deigma. O como una fórmula, tal como diría Deleuze a propósito de Bartleby. Pero el concepto mismo de comentario (la forma) se equivale al contenido (la práctica) de su lectura y esa equivalencia entre significante y significado, recordemos, es definitoria del princípio

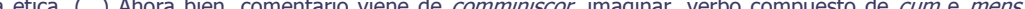

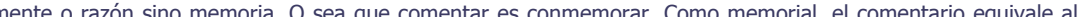
cuaderno de notas, al diario, o sea a aquellas anotaciones, realizadas al margen de un texto, que constituyen su marginalia, haciendo que el texto dialogue así con la historia. En ese sentido son auténticos comentarios los balbuceos de la vanguardia latinoamericana, registrados en cuadernos: Cuaderno San Martín, Primeiro caderno do aluno de poesia Oswald de Andrade, los cuadernos de viaje de Oliverio Girondo, sus Calcomanías, meras imágenes de contacto, o las Metamorfosis del dadaista Jacques Edwards, el escritor chileno Joaquín Edwards Bello. Recordemos, además, que commentum, en Roma (...) equivalía a ficción, a cosa imaginada, a plano o proyecto. De donde, ante esa concepción fragmentaria de la obra de arte, nos deparamos, pues, no sólo con lo irrepresentable, sino también con lo inmemorial". Por lo demás, fue a través del nominalismo que la vanguardia dadaísta intuyó que sonidos y contactos eran mejores vehículos que las imágenes para expresar ese interstício dimensional infraleve. El lenguaje como nueva tactilidad se vuelve entonces herramienta indispensable para captar la pluridimensionalidad de la experiencia". Cf. ANTELO, Raul - "La des-obra como ready-made" in PREMAT, Julio (ed.), Quimeras. Cuando la literatura sabe, ve, piensa, Cahiers de LI.RI.CO. $\mathrm{n}^{\circ} 4$, Saint Denis, Université Paris 8 (no prelo).

[14]Cf. NANCY, Jean-Luc - Del libro e della librería. Il commercio delle idee. Milán, Raffaello Cortina, 2006, p. 31-2.

[15] Cf HERVE, Roger - "Sacrifices Humains du Centre-Amérique" in Documents, a.2, no 4, Paris, 1930, p. 205-213. 
[16] Cf KOENIGSWAKD, Ralph von - "Têtes et crânes". Documents, a.2, no 6, Paris, 1930, p. 353-358

[17] Cf. LEIRIS, Michel - "Le caput mortuum ou la femme de l'alchimiste". Documents, a., no 8, 1930, p.2126.

[18] Cf. DUTHUIT, Georges - "Representations de la mort". Cahiers d'Art, a. 14, no 1, Paris, 1939, p. 25-39

[19] Cf. BATAILLE, Georges - "La mutilation sacrificielle et I 'oreille coupée de Vincent van Gogh". Documents. 2, no 8, Paris,

1930, p.11-20.

[20] Cf BARTHES, Roland - "Entre as coisas e as palavras" in Sistema da moda. Trad. Lineide do Lago Salvador Mosca.São Paulo, Nacional, 1979, p.27-41 e "Entre le plaisir du texte et I'utopie de la pensée" in CEuvres complètes. Tome III, 1974-1980. Édition établie et présentée par Éric Marty. S. I.: Éditions du Seuil, 1994, p.888-894.

[21] Cf. NANCY, Jean-Luc - La creación del mundo o la globalización. Trad. P.P.Velamazán. Barcelona, Paidós, 2003, p.121143.

[22] Cf. DERRIDA, Jacques - Inconditionnalité ou souveraineté. L'Université aux frontières de l'Europe, Atenas, Patakis, 2002, p. 50.

[23] Cf REGAZZONI, Simone - La decostruzione del politico. Undici tesi su Derrida. Il Nuovo Melangolo. Genova, 2006.

[24] Cf. O'ROURKE, Michael - "Queer Theory's Loss and the Work of Mourning Jacques Derrida" in rhizomes, nº10, spring 2005.

[25] Cf. LEIRIS, Michel - -"L'Ile magique", Documents, a.1, no 6,1929, p.334; IDEM "L'oeil de l'ethnographe" Documents, a.2, n07,1930, p.405-14 e IDEM - "Le 'caput mortuum' ou la femme de l'alchimiste", Documents, a.2, no8, 1930, p. 461-6. Cf. KELLY, Julia - Art, Ethnography and the Life of Objects, Paris c. 1925-1935. Manchester University Press, 2007.

[26] Cf. DIDI HUBERMAN, Georges - Ante el tiempo. Historia del arte y anacronismo de las imágenes. Buenos Aires, Adriana Hidalgo, 2006; IDEM - Imágenes pese a todo: memoria visual del holocausto, Barcelona, Paidós, 2004; IDEM - Venus rajada: desnudez, sueño, crueldad, Madrid, Losada, 2005; IDEM - Lo que vemos, lo que nos mira, Buenos Aires, Manantial, 2004; IDEM - La distancia y la huella: para una antropología de la mirada, Cuenca, Diputación Provincial, 2001.

[27] Cf. LACLAU, Ernesto - "¿Por qué construir al pueblo es la principal tarea de una política radical?" In Debates y combates. Por un nuevo horizonte de la política. Buenos Aires. Fondo de Cultura Económica, 2008, p.42.

[28]BATAILLE, Georges. El límite de lo útil (fragmentos de una versión abandonada de La Parte maldita). Trad. Manuel Arranz. Madrid, Losada, 2005, p.29-30.

[29] Cf. DEBORD, Guy - A sociedade do espetáculo. Comentários sobre a sociedade do espetáculo. Trad. Estela dos Santos Abreu. Rio de Janeiro, Contraponto, 1997, p.29-30.

[30] Cf. BATAILLE, Georges - "Les Pieds nickelés". Documents, a.2, no 4, Paris, 1930, p.215-6.

[31] Na resenha, H. Moore argumenta que "the Sumerians were an agricultural and pastoral people, and they had their poets and perhaps scholars - astronomers and learned men. Their art dates from the birth of civilisation, so that most of the work reproduced in L'Art de la Mésopotamie was made between 5.000 and 4.000 years ago. But it is not necessary to know their history in order to appreciate and respond to these works of art. We need to look at them as sculpture, for once a good piece of sculpture has been produced, even if it was made like the paleolithic 'Venuses' 20.000 years ago, it is real and a part of life, here and now, to those sensitive and open enough to feel and perceive it. For me, Sumerian sculpture ranks with Early Greek, Etruscan, Ancient Mexican, Fourth and Twelfth Dynastry Egyptian and Romanesque and Early Gothic sculpture, of the world. It shows a richness of feeling for life and its wonder and mystery, welded to direct plastic statement born of a real creative urge. It has a bigness and simplicity with no decorative trimmings (which are the sign of decadence, of flagging inspiration). But for me its greatest achievement is found in the free-standing pieces - sculpture in the round, which is fullest sculptural expression - and these have tremendous power and yet sensitiveness. The sculpture of most early periods, even when carved from a block and not from a slab, is not fully realised form, it is relief carving on the surface of the block; but these Sumerian figures have full three-dimensional existence. (...) The photographs in L'Art de la Mésopotamie are by M. Horacio Coppola, and they cannot be overpraised. As a substitute or as an introduction to the actual sculptures good photographs are very useful. In illustrated books on sculpture the photographs should be the best possible and well reproduced, or the book loses half its value. Most people, I think, respond more easily and quickly to a flat image than to a solid object (this may partly explain why sculpture seems to be a more difficult art to appreciate than painting). I have often noticed that people, after seeing a good photograph of a piece of sculpture which until then they had more or less ignored, find their interest in the original greatly increased. The real appreciation of sculpture comes from seeing and comprehending it in its full three-dimensional volume, but if a photograph leads people to see the original, then it has been of value". A seguir, H. Moore destaca a questão do tamanho, ligado ao processo de abstração e compreensão da obra: "Some of the photographs in M. Zervos' book are many times larger than the original works. To see a piece one knows to be only 2 or 3 inches high, looking several times its real size comes as a great surprise - but I think it is legitimate tu use any means which help to reveal the qualities of the work. A further justification for these enlarged photographs is that they may draw attention to very fine small pieces which, exhibited in a crowded collection, can easily be overlooked. Another point raised by these small figures seen suddenly enlarged four or five times, is the importance of size in sculpture. These small figures, seen so much bigger, take on an extra importance and impressiveness, and are a proof that size itself has an emotional value. But size alone should not in sculpture become of main importance. There is a limit at which the control of the unity of the parts to the whole becomes physically too difficult - and when the love of size becomes a love of the colossal it results in insensitiveness and vulgarity" (The Listener, 5 jun. 1935). Cf. MOORE, Henry - Writings and conversations. Edited and with an introduction by Alan Wilkinson. Berkeley, University of California Press, 2002, p. 944-6.

[32] Cf. BERNI, Antonio - "Los huacos-retratos" in Forma. Revista de Artes Plásticas, no 27, Buenos Aires, jun. 1943, p.13.

[33] Cf. NANCY, Jean-Luc - La mirada del retrato. Trad. I. Agoff. Buenos Aires, Amorrortu, 2006, p.24-5.

[34] Trata-se de uma intervenção pioneira na linha do que, mais tarde, a partir de 1966, o psicanalista Enrique Pichon-Rivière desenvolveria na revista Primera Plana. È o momento em que a psicanálise auxilia a antropologia a interpretar as grandes narrativas populares, tal como nos trabalhos de Arthur Ramos, no Brasil, ou Bernardo Canal-Feijóo, na Argentina.

[35] Cf. GERMANI, Gino - Authoritarianism, fascism and national populism. New Brunswick, Transaction Books, 1978; IDEM The sociology of modernization. Studies on its historical and theoretical aspects with special regard to the Latin American case. New Brunswick, Transaction Books, 1981; IDEM - Estudios sobre sociologia y psicologia social. Buenos Aires, Paidós, 1971 e, por último, Politica y sociedad en una epoca de transición: de la sociedad tradicional a la sociedad de masas. Buenos Aires, Paidós, 1962.

[36] Para as fotomontagens, ver STERN, Grete - Sueños. Valencia, Centre Julio González,1995.

[37] Cf. PRÍAMO, Luis - "Los sueños de Grete Stern" in Sueños. Valencia, IVAM, 1995

[38] Cf. DERRIDA, Jacques - Droit de regards. Paris, Minuit, 1985.

[39] SLOTERDIJK, Peter - Règles pour le parc humain. Une lettre en réponse à la Lettre sur l' humanisme de Heidegger. Trad. O. Mannoni. Paris, Mille et une nuits,2000. Laurent Milesi aborda essa questão dos limites do humanismo em "Zo(o) graphies. Evolutions darwiniennes de quelques fictions animales" in MALLET, Marie Louise (ed.) - L'animal autobiographique. Autour de Jacques Derrida. Paris, Galilée, 1999, p. 11-46.

[40] Em "On the Void: The Fascinating Object of Evil in Human Remains", o filme de Jay Rosenblatt, a crítica Garnet C. Butchart pondera que "despite its apparent absence, however, this remainder is not simply invisible. Rather, in its resistance to symbolisation, the Real presents itself as a gap or void in the signifying chain, a symbolic impossibility that the chain is forced to avoid. It is in this sense that Lacan says the remains of the Real appear most fully in the form of "nothing," of what is pushed aside or left out of a signifying chain, what he calls the caput mortuum of the signifier. Since the process of signification involves the inscription of one signifier in the place of another within the signifying chain, the caput mortuum - that which is excluded from the chain - determines the very structure of the chain; there must be an outside of the chain for there to be excluded from the chain - determines the very structure of the chain; there must be an outside of the chain for there to be
anything inside it. A signifying chain therefore never ceases to inscribe the caput mortuum, forming around them as a rule of logic; the remains of the symbolic process are carried along the chain as external-internal cause of its unfolding. As that which remains to be symbolised, the Real in this way appears as the truth of a signifying chain, the void in the chain that stands out as the unspeakable thing missing from the chain in its evasion of what cannot be put into words. It is the thing that, in Žižek's words, "persists only as failed, missed, in a shadow, dissolves itself as soon as we try to grasp it in its positive nature." In short-resume Butchart-the Real recurs to reality, haunting the appearance of the symbol in its murder of the thing". Apoiada em Alenka Zupančič (Ethics of the Real: Kant, Lacan. Londres, Verso, 2000, p. 191) destaca que o fundamental é que "the remainder of the self referential dynamic of the signifier itself, not simply some piece of matter that the signifier was unable to integrate into the Symbolic order. Insofar as signifiers refer not to things but to other signifiers, the remainder of this process that which the signifying chain fails to signify, namely, its cause -retroactively determines the dimension of the Thing". Cf. BUTCHART, Garnet C. - "On the Void: The Fascinating Object of Evil in Human Remains". In NORDEN, Martin (ed.) - The Changing Face of Evil in Film and Television. Amsterdam/New York, NY, Rodopi, 2007, p.159-175. 
[41] Cf. LACAN, Jacques - "Le Séminaire sur La lettre voile" in Écrits. Paris, Seuil, 1966, p.50. Lacan retoma a expressão em várias outras oportunidades. Dois anos depois do seminário sobre a carta roubada, em 1957, o termo aparece no Seminário IV, aula 14; retorna, ainda, no Seminário 11, sobre os quatro conceitos, em 1964, e mesmo em 1972, no Seminário 19 bis, sobre o pior, mais uma vez, tornará a aparecer o velho conceito de caput mortuum.

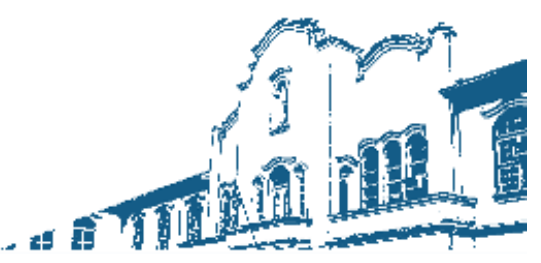

Copyright PPGCL/ Unisul 2006 @ (48) 3621-3369 - Desenvolvimento: Prof. Dr. Fábio J osé Rauen 